\title{
O conceito de "campo" em sala de aula - uma abordagem histórico-conceitual
}

(The concept of field in the classroom - a historical-conceptual approach)

\author{
José Fernando Moura Rocha ${ }^{1}$ \\ Instituto de Física, Universidade Federal da Bahia, Campus de Ondina, Salvador, BA, Brasil \\ Recebido em 24/5/2008; Revisado em 3/10/2008; Aceito em 20/10/2008; Publicado em 30/4/2009
}

\begin{abstract}
O conceito de campo é uma das idéias fundamentais da física e pode motivar um rico debate em sala de aula sobre as noções básicas desta ciência. Apesar de sua importância, quando o mesmo é apresentado em sala de aula geralmente somente seus aspectos matemático-conceituais são enfatizados deixando-se em segundo plano os aspectos histórico-conceituais, quando estes não são simplesmente ignorados. Neste trabalho, pretendemos mostrar que uma apresentação com ênfase apenas matemático-conceitual deste conceito não explora toda a sua potencialidade. Com tal propósito, primeiro consideramos a noção de campo como algo responsável pela mediação de interação entre os corpos e depois tratamos a noção de campo como uma função matemática das coordenadas e do tempo. Em seguida, mostramos que o conceito de campo, na forma que o entendemos hoje, resultou de um complexo processo de fusão destas duas concepções.
\end{abstract}

Palavras-chave: campo, éter, ensino de física, história da física.

The concept of a field can motivate a rich class-forum about the basic notions of physics. Despite its importance, only mathematical-conceptual aspects are emphasized in the classroom, leaving out historical-conceptual aspects. We believe that only the mathematical-conceptual presentation of this concept underestimates all its strength. We show in this paper how this physics concept can be introduced from two different but converging ways, First, we consider the notion of the field as something responsible for the mediation of interaction between bodies and then we treat it as a mathematical function of the coordinates and time. Next, we show that, in a complex process, these two conceptions have been merged towards the concept of field as we understand it nowadays.

Keywords: field, ether, physics teaching, history of physics.

\section{Introdução}

O conceito de campo é uma das noções fundamentais da física. Este conceito se consolidou ao longo do século XIX, quando se revelou uma das mais importantes invenções desde o tempo de Newton. Apesar de sua importância, quando o mesmo é apresentado em sala de aula, no contexto do ensino de eletricidade e magnetismo para alunos do segundo ano universitário da área de ciências exatas, geralmente só são enfatizados seus aspectos matemático-conceituais, deixandose os aspectos histórico-conceituais em segundo plano, quando estes não são simplesmente ignorados. Esta é a nossa experiência pessoal e provavelmente não deve ser uma experiência isolada. Acreditamos, entretanto, que a idéia de campo pode motivar um rico debate sobre as idéias da física e consideramos que uma apre-

\footnotetext{
${ }^{1}$ E-mail: jofer@ufba.br.

sentação apenas matemático-conceitual deste conceito não explora toda a sua potencialidade. Isto é o que procuraremos evidenciar neste trabalho.

Para facilitar nossa apresentação, vamos seguir dois caminhos diferentes e convergentes através dos quais o conceito de campo começou a ser formulado. De um lado, consideraremos a noção de campo como algo responsável pela mediação da interação entre os corpos a uma certa distância um do outro e que poderia ser considerado como uma alternativa à idéia de ação a distância. Do outro, trataremos a noção de campo como uma função matemática das coordenadas e do tempo, noção essa que foi inicialmente utilizada para descrever propriedades físicas da matéria nos casos em que a mesma era tratada como contínua, a exemplo do campo de temperatura. 


\section{As primeiras idéias de campo}

A questão da transmissão da força tem sido trazida à baila de tempos em tempos. Não faremos um estudo exaustivo de como esta questão evoluiu desde tempos remotos. Aqui, dirigiremos nossa atenção especialmente para a evolução do conceito de campo como um meio de transmissão da força, sem deixar de falar na idéia de ação a distância. Para os nossos propósitos, é suficiente discutirmos a gênese do conceito de campo a partir das idéias de estudiosos antigos que procuraram explicar os efeitos produzidos pela magnetita ou pelo âmbar atritado. Tentativas relevantes para explicar a ação da magnetita foram realizadas, por exemplo, por Tito Lucrécio Caro, um poeta latino (romano), que viveu entre 95 e 52 a.C., e pelo cientista inglês William Gilbert (1544-1603) (Fig. 1) que, após estudar medicina em Cambridge, estabeleceuse em Londres, por volta de 1570. Vamos expor as idéias de ambos sobre este assunto, mas começaremos mostrando as idéias de Gilbert, a respeito da atração entre a magnetita e o ferro, pelo fato de as mesmas estarem relacionadas apenas a campos clássicos (os efeitos produzidos pelo âmbar atritado, Gilbert explicava de outra maneira). Em seguida, discutiremos as idéias de Lucrécio, por lembrarem, de algum modo, o conceito de campo quântico (ou quantizado), salientando aqui que esta analogia diz respeito apenas a forma de descrever o fenômeno e não ao conteúdo da teoria.

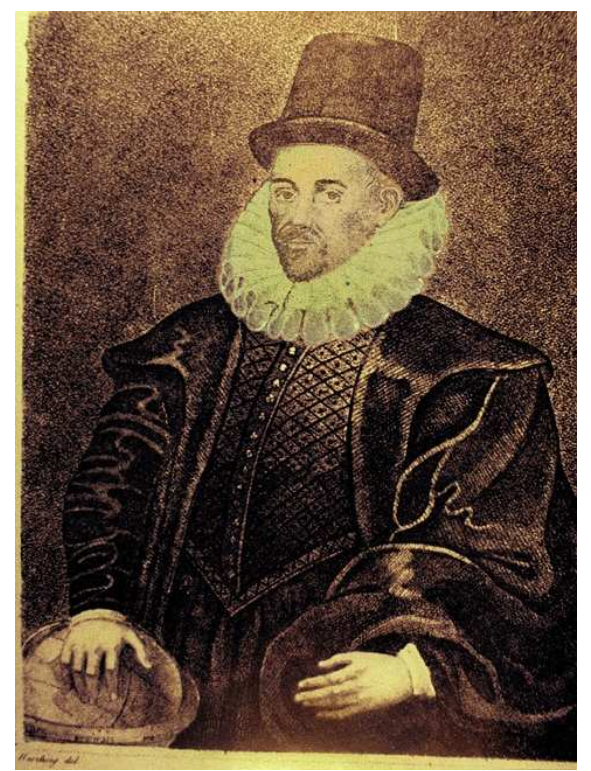

Figura 1 - Willian Gilbert.

Vejamos o que nos diz Gilbert a respeito da força do imã sobre o ferro, no seu livro De Magnete, publicado em latim, em 1600 d.C. ([1, p. 121], [2, p. 34]):

A força da terrela [mini-terra] estende-se em todas as direções... Mas sempre que o ferro ou outro corpo magnetizado de tamanho suficiente entra na sua esfera de influência é atraído; no entanto, quanto mais de perto estiver a magnetita, maior será a força com que ela o atrai.

No parágrafo anterior, vemos a forma como Gilbert descreve a força que a magnetita exerce sobre outro corpo imantado. Este é um passo importante na formulação do conceito de campo, entendendo aqui por campo uma propriedade física que se estende por uma região do espaço e é descrita por uma função da posição e do tempo.

Gilbert apresentou as idéias acima citadas após rever e criticar outras teorias então existentes, propostas para explicar a causa da atração magnética, a exemplo da explicação apresentada por Lucrécio - uma das mais populares na época - no seu célebre $D a N a$ tureza (De Natura Rerum, título original latino). Apesar de Gilbert não aprovar as idéias de Lucrécio sobre a atração magnética, hoje as mesmas podem nos fazer lembrar a idéia de campo quantizado, de acordo com a qual uma partícula carregada está geralmente cercada de uma nuvem de fótons (que a partícula emite e absorve) e outras partículas, conforme esclareceremos adiante (ver também Figs. 2 e 3). Vejamos o que nos diz Lucrécio [3]:

Vou agora começar a explicar outro assunto, a dizer por que leis naturais podem atrair ao ferro a pedra a que chamam os gregos magneto, nome que lhe designa a origem, porquanto se diz que provém de Magnésia. [...] É necessário primeiro que saiam desta pedra numerosos elementos ou uma corrente [átomos do magneto] que por seus golpes dissipe o ar que se encontra colocado entre a pedra e o ferro. Logo que o espaço se encontra vazio, logo que se despeja o lugar que está no meio, imediatamente os elementos do ferro, caindo, se lançam juntos no vácuo, de maneira que o próprio anel os segue e vai com toda a sua substância. [...]

Lucrécio estende sua explicação (teoria do "effluvium") por mais parágrafos, mas, para os nossos propósitos, será suficiente restringimo-nos ao resumo destas suas idéias feito por Gilbert, em 1600 ([1, p. 5]):

Lucrécio Caro, poeta epicurista, considera que a atração é devida ao fato de que, assim como em todas as coisas há um fluxo para fora ["efluxo"] de corpos minúsculos, assim também há um efluxo de átomos do ferro para o espaço entre este e a magnetita 
- um espaço esvaziado de ar pelos átomos da magnetita (sementes ${ }^{2}$ ); e quando estes átomos começam a voltar para a magnetita, o ferro segue-os, pois os corpúsculos estão emaranhados uns nos outros.

Para vermos como estas idéias podem nos fazer lembrar o conceito de campo quantizado, vamos, a seguir, apresentar a idéia de um campo quantizado, e também como se dá, na chamada eletrodinâmica quântica, a interação (atração, neste caso) entre duas partículas um elétron e um próton, por exemplo. Para facilitar o entendimento, vamos começar relembrando o caso clássico e, em seguida, discutir o caso quântico. No caso clássico, um elétron tem associado a ele um campo que ocupa todo o espaço; numa linguagem figurada, o elétron tem uma "aura" em torno de si, (entendendo esta "aura" como algo sutil, tênue, mas real; Fig. 2); o próton, por sua vez, está no campo do elétron e, por isso, sente uma força. No caso quântico, admite-se que o elétron (ou outra partícula carregada $)^{3}$ está geralmente cercado de uma nuvem de fótons (que podem decair em outras partículas) que ele emite e absorve (diz-se então que o elétron está "vestido"; Fig. 3; [4]); o próton (que geralmente encontrar-se "vestido" também), estando imerso na nuvem do elétron, pode absorver um dos fótons que o elétron emitir. Neste caso, dizemos que existe uma troca de informações entre eles, o que corresponde aos efeitos de uma força. Observamos então que, no caso clássico, o campo é visto como uma espécie de "substância eletromagnética" com uma única estrutura, enquanto que no caso quântico, procura-se especificar a estrutura do campo em termos de partículas. Comparemos agora a noção de campo quantizado com aquela apresentada por Lucrécio para explicar a interação entre a magnetita e o ferro. Notamos inicialmente que a emissão e absorção dos átomos da magnetita, pela própria magnetita, lembra a emissão e absorção dos fótons pelos elétrons, no caso quântico. Um outro aspecto é o aparecimento da força como uma consequência da existência de partículas em volta das fontes do campo; no caso da magnetita, seria uma consequência dos átomos da magnetita emaranhar-se com os átomos de ferro, no momento da volta daqueles para a própria magnetita; enquanto, no caso do elétron, seria uma consequência de as partículas emitidas pelo elétron serem absorvidas pelo próton (imerso na nuvem de partículas que constitui o campo quantizado do elétron). De qualquer forma, a interação ocorre através de um agente intermediário e não por ação direta entre a magnetita e o ferro. Apesar das analogias possíveis, não podemos esquecer as diferenças. Primeiro, existe uma diferença de escala no que diz respeito às dimensões dos objetos interagentes. No caso do elétron e do próton, as partículas do campo são emitidas e/ou absorvidas por objetos microscópicos; no caso da magnetita e do ferro, as partículas do campo são emitidas e absorvidas por objetos macroscópicos, escala em que propriedades quânticas não são normalmente relevantes. Em segundo lugar, a estrutura do campo quântico é formada pela soma das probabilidades de efeitos diferentes, enquanto a estrutura do campo da magnetita é formada por um conjunto de partículas semelhantes, não envolvendo a idéia de probabilidade, um dos conceitos fundamentais da eletrodinâmica quântica. Finalmente, a eletrodinâmica quântica é uma teoria apoiada em um sofisticado formalismo matemático, o que naturalmente não é o caso da "teoria do effluvium", de Lucrécio.

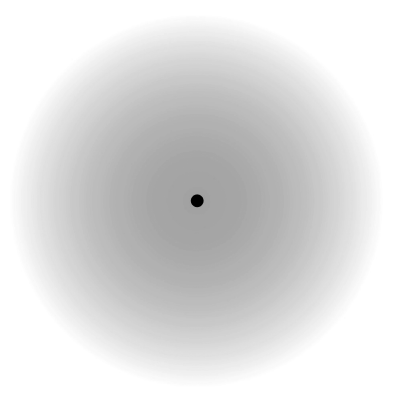

Figura 2 - Representação de um campo clássico através de sua "aura", continua e homogênea, para o caso de uma carga pontual ou de uma massa pontual, entendendo por "aura" algo sutil, mas real, sem sentido místico.

Ainda no século XVII, muito antes do físico e químico Michael Faraday (1791-1867) adotar a frutífera idéia de linhas de força, outros cientistas avançaram na noção clássica de que objetos estariam rodeados por "atmosferas" que se estendiam até regiões mais distantes e que tais "atmosferas" transmitiriam as forças gravitacionais, elétricas e magnéticas de um corpo para outro. Mas estas eram teorias apenas qualitativas e não tiveram o alcance dos trabalhos desenvolvidos por Faraday, conforme veremos mais adiante.

\footnotetext{
2 "Sementes" provavelmente no sentido dado por Anaxágoras (cerca de 500-428 a.C.). A natureza de uma coisa é determinada pelas "sementes" que nela prevalecem. Parece ouro aquela em que prevalecem as partículas de ouro, embora haja nela partículas de todas as outras substâncias. As "sementes" são os elementos dos quais derivariam todas as coisas.

${ }^{3}$ Hoje sabemos que partículas microscópicas, tais como elétrons e prótons, exibem comportamento quântico, o que não era conhecido até o início do século XX. A teoria conhecida como eletrodinâmica quântica incorpora efeitos quânticos na teoria eletromagnética clássica. No âmbito da física quântica, tais efeitos podem ser considerados de dois modos ou níveis diferentes. No primeiro nível, considera-se o campo do elétron como sendo clássico e distribuído no espaço de modo contínuo; a discussão do átomo de hidrogênio encontrada nos livros-textos serve para exemplificar este caso, pois nele se estuda estados estacionários de um elétron quântico num campo eletromagnético clássico. Um outro nível é aquele em que o campo também é quantizado; este é o caso ao qual nos referimos no texto. A quantização do campo ("segunda quantização") foi realizada por Paul Dirac, em 1927.
} 
(a)

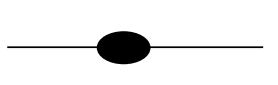

elétron vestido

(1) (b)

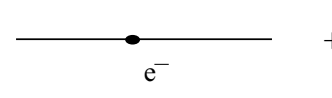

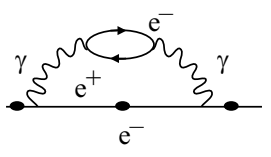

(d)
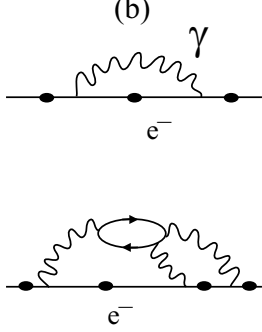

(e) (c)

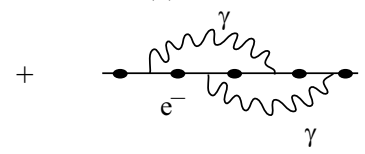

Figura 3 - Representação da estrutura do campo quântico. Vemos um elétron "vestido" e a estrutura de seu campo a qual é dada pela soma das probabilidades de vários efeitos diferentes, envolvendo fótons. Considera-se aqui o elétron livre, com momento bem definido. A "aura" do elétron neste caso tem uma estrutura constituída de fótons e pares elétron-pósitron. Cada um dos processos (a, b, c, d, e) tem uma probabilidade característica de ocorrer. Existe uma probabilidade desse elétron se propagar sem "aura" (Fig. 3.a). Pode também gerar uma "aura", emitindo fótons e reabsorvendo-os como mostra a Fig. 3.b. Pode emitir um fóton que decai num par e $\mathrm{e}^{+}$, que se aniquilam, emitindo outro fóton, que é absorvido pelo elétron original (Fig. 3.d). E assim por diante (adaptado de M.R. Robilotta et al., [4]).

\section{A origem da doutrina da ação direta (ação a distância)}

O período que abrange aproximadamente a segunda metade do século XVI e todo o século XVII foi de profundas transformações nas ciências. Essa é a época da chamada revolução científica. É o período da valorização da observação e da experimentação na abordagem dos fenômenos naturais, bem como da compreensão da importância do uso da matemática na descrição desses fenômenos. É, portanto, um período de profundas mudanças no modo de se fazer ciências. Idéias antigas, a exemplo das que atribuíam à magnetita uma espécie de alma que se manifestaria nas suas propriedades magnéticas ${ }^{4}$ ou das que explicavam a atração elétrica por uma simpatia entre os corpos interagentes (esta comum na Idade Média) passavam agora por um novo "critério de validade".

É nesse contexto de renovação que, em 1687, Isaac Newton (1642-1727) publica sua preciosa obra denominada Philosophiae Naturalis Principia Mathematica (Princípios Matemáticos de Filosofia Natural), na qual ele apresenta sua lei de gravitação universal que, matematicamente, costuma ser escrita (em módulo) na forma: $F=G m_{1} m_{2} / r^{2}$. Através dessa obra, Newton explica como os corpos materiais interagem, mas não explica o mecanismo pelo qual esses corpos o fazem, ficando, portanto, um espaço para especulações. Sem explicar o mecanismo pelo qual os corpos se atraíam, a lei da gravitação universal permitia a suposição (não por Newton) de que as interações entre os corpos eram do tipo ação a distância, sem a necessidade de um meio para mediar tais interações. Por essa razão, muitos passaram a crer que também Newton defendesse a idéia de ação a distancia. No seu artigo de 1873, denominado Ação a Distância [5], James Clerk Maxwell (1831-1879) afirma que foi o matemático e físico inglês Roger Cotes (1682-1716) (Fig. 4) quem primeiro afirmou a doutrina da ação direta, em seu prefácio à $2^{\mathrm{a}}$ edição do Principia (1713), que o mesmo editou durante a vida de Newton. Nesse citado artigo, Maxwell escreve que de acordo com Cotes $[5,7]$ :

[...] é pela experiência que aprendemos que todos os corpos gravitam. Não é de nenhum outro modo que aprendemos que eles têm extensão, que são capazes de mover-se ou que são sólidos. Portanto a gravitação tem tanto direito de ser considerada uma propriedade essencial da matéria quanto a sua extensão, a mobilidade ou a sua impenetrabilidade.

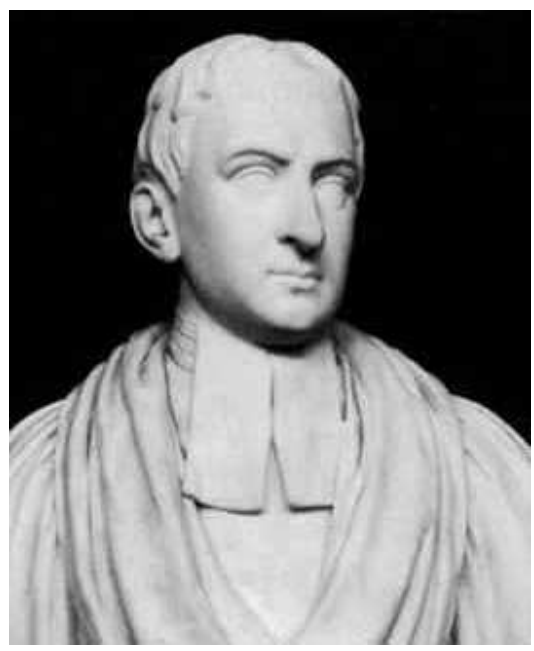

Figura 4 - Roger Cotes. Matemático, físico e professor em Cambridge. Desenvolveu trabalhos para a teoria de logaritmos, o cálculo integral e métodos numéricos. Foi encarregado por Richard Bentley (ver Fig. 5) da $2^{a}$ edição do Principia, da qual escreveu o Prefácio. Faleceu jovem, com 34 anos.

\footnotetext{
${ }^{4}$ De acordo com Aristóteles "Parece que Tales, pelo que se conta, supôs que a alma é algo que se move, se é que disse que a pedra (imã) tem alma, porque move o ferro" (Ref. [6]).
} 
O problema de a gravidade ser ou não uma "propriedade essencial e inerente à matéria" (o que significaria a matéria inanimada agir sobre outra matéria sem a mediação de alguma outra coisa, não material), entretanto, é anterior a 1713, e o próprio Newton já tinha esclarecido sua posição sobre este problema, em cartas escritas ao clérigo e filósofo inglês Richard Bentley (1662-1742) (Fig. 5).

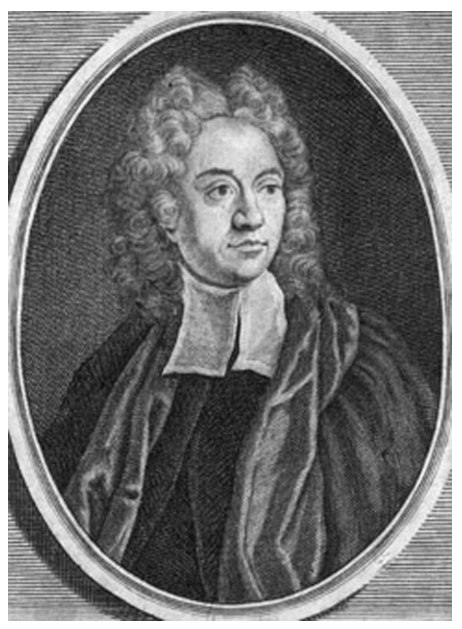

Figura 5 - Richard Bentley. As cartas de Newton a Bentley, referidas no texto, foram escritas após Bentley ser indicado para dar o primeiro conjunto de aulas em defesa da religião estabelecidas pelo testamento do cientista inglês Robert Boyle (1627-1691). Bentley se pautou maciçamente nas teorias de Newton.

Em 17 de janeiro de 1693, Newton escreveu a Bentley $[8]$ :

[...] O Sr. algumas vezes fala da gravidade como sendo essencial e inerente à matéria. Peço-lhe não atribuir essa noção a mim, pois a causa da gravidade é o que eu não pretendo saber, e portanto levaria muito tempo para considerá-la.

Em 25 de fevereiro de 1693, em outra carta a Bentley, Newton escreveu [8]:

[... É inconcebível que a matéria bruta, inanimada, opere sem a mediação de alguma outra coisa, não-material, sobre outra matéria e a afete sem contato mútuo, como deve ocorrer se a gravitação, no sentido de Epicuro, for essencial e inerente a ela; E é por esta razão que desejei que você não atribuísse a gravidade inata a mim. Que a gravidade devesse ser inata, inerente e essencial à matéria de modo que um corpo pudesse atuar sobre outro a distância através de um vácuo, sem a mediação de qualquer coisa, por cujo intermédio sua ação e força pudesse ser transmitida de um corpo para outro é para mim um absurdo tão grande que acredito que nenhum homem dotado de uma faculdade de pensamento competente em questões filosóficas jamais possa cair nele. A gravidade deve ser causada por um agente que atua constantemente de acordo com certas leis; mas se esse agente é material ou imaterial é uma consideração que deixo para meus leitores.

Para alguns filósofos da época de Newton, a doutrina da gravitação era um retorno ao "método já bastante surrado de explicar todas as coisas por meio de causas ocultas, virtudes atrativas ou coisas desse tipo".

Apesar de haver discordância, as idéias que prevaleceram, na gravitação e também na eletricidade e no magnetismo foram, até as primeiras décadas do século XIX, as de ação a distância. C. Coulomb (1736-1806), A. Ampère (1775-1836), H. Cavendish (1731-1810) e S. Poisson (1781-1840), por exemplo, não se preocuparam com as noções antigas de eflúvios magnéticos e atmosferas elétricas. Muitos cientistas, porém, sentiam que as teorias de ação a distância, apesar de conduzirem à previsões corretas, não conseguiam fornecer uma explicação física satisfatória para o modo como um corpo exerce uma força sobre o outro.

No início do século XIX, entretanto, reviveu-se o conceito de atmosfera que rodeava os objetos, mesmo que dentro de um contexto bastante diferente daquele do século XVII. Em meados do citado século XIX, contudo, a idéia de atmosfera foi superada por um novo e poderoso conceito adotado por Michael Faraday (Fig. 6) para descrever as interações eletromagnéticas: o conceito de linhas de força. E é isto o que veremos a seguir.

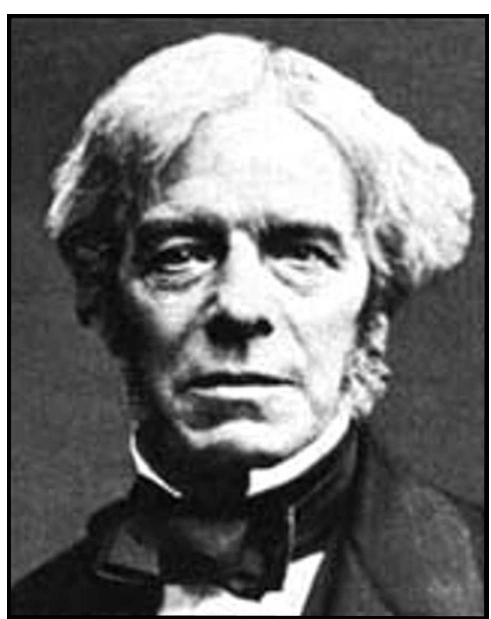

Figura 6 - Michael Faraday.

\section{O campo de Faraday - linhas de força}

As contribuições de Faraday para o eletromagnetismo começaram em 1821, quando o editor da revista $A n$ nals of Philosophy solicitou-lhe que escrevesse um resumo sobre as experiências e teorias eletromagnéticas, 
que tinham aparecido no ano anterior, como consequência dos trabalhos de Hans Oersted (1777-1851) e outros. Não demorou muito para Faraday perceber que não poderia só relatar o que existia e passou a fazer suas próprias experiências. No curso destas suas experiências, após observar figuras de limalhas de ferro produzidas por um imã colocado sob uma folha de papel ou lâmina de vidro (Fig. 7) (figuras semelhantes já haviam sido observadas na época medieval por Pierre de Maricourt) ${ }^{5}$ Faraday passou a visualizar as forças magnéticas e elétricas como uma espécie de tubos de borracha ou linhas elásticas que se estendiam no espaço a partir de imãs ou de corpos eletrizados e que podiam ser distorcidas, as quais ele denominou linhas de força. Como essas linhas deveriam preencher o espaço vazio este passava a constituir-se em um campo de forças.

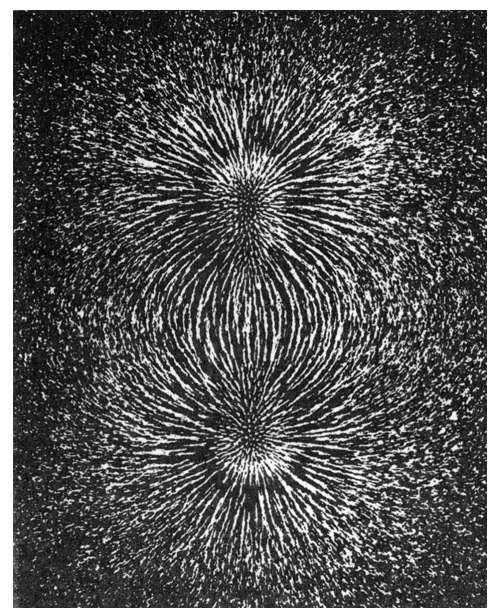

Figura 7 - Visualização das linhas de força através de limalhas de ferro espalhadas sobre uma folha e papel, tendo uma barra imantada sob a mesma (adaptado do livro Fundamentos de Física, de Halliday e Resnick [9]).

Ao se referir aos experimentos com limalhas de ferro, realizadas por Faraday, nos quais podem-se visualizar as chamadas linhas de força, Maxwell, no citado artigo de 1873, afirma [5]:

Mas Faraday, por meio de uma série de passos notáveis por sua precisão geométrica, assim como pela sua engenhosidade especulativa, deu a sua concepção de linhas de força uma clareza e uma precisão bem maior do que aquela que os matemáticos de então poderiam extrair de suas próprias fórmulas.

Em primeiro lugar as linhas de força de Faraday não devem ser consideradas isoladamente, mas sim como um sistema traçado no espaço de uma maneira definida, de tal forma que o número de linhas que atravessam uma área, digamos de uma polegada quadrada, indica a intensidade da força através da mesma. Assim as linhas de força tornam-se bem definidas em número. A intensidade de um pólo magnético é medida pelo número de linhas que procedem dele; a força eletromotriz de um circuito é medida pelo número de linhas de força que passam através dele.

Em segundo lugar, cada linha individual tem uma existência contínua. Quando um pedaço de aço torna-se um ímã, ou quando uma corrente elétrica começa a fluir, as linhas de força não passam a existir cada uma delas em seu próprio lugar, mas à medida que a intensidade aumenta novas linhas são geradas dentro do ímã ou corrente e gradualmente crescem em direção ao exterior, de maneira que todo o sistema se expande de dentro para fora ...

...Por meio deste novo simbolismo, Faraday definiu com precisão matemática toda a teoria do eletromagnetismo em uma linguagem livre de tecnicismos matemáticos, e aplicável aos casos mais complicados bem como aos mais simples. Mas Faraday não parou por aqui. Ele prosseguiu da concepção geométrica de linhas de força para a concepção física. Ele observou que o movimento que a força elétrica ou a magnética tendem a gerar é invariavelmente tal como para encurtar as linhas de força ao mesmo tempo em que permite que se afastem lateralmente umas das outras. Assim ele percebeu no meio um estado de tensão que consiste em uma tração como a que existe em uma corda esticada, na direção das linhas de força, combinada com uma pressão em todas as direções, mas formando um ângulo reto com essas linhas.

Essa é uma concepção bastante diferente de ação a distância, reduzindo-a a um fenômeno do mesmo tipo que aquela ação a distância que é exercida por meio de tensão de cordas e pressão de bastões. Quando os músculos de nossos corpos são excitados por um estímulo ao qual somos capazes de uma maneira desconhecida de responder, as fibras tendem a encurtar-se e ao mesmo tempo expandir lateralmente. Um estado de tração se produz no músculo e o membro se move. ...Por razões similares podemos considerar a concepção de Faraday de estado de tensão de um campo eletromagnético como um método de explicar a ação a distância por meio de uma trans-

\footnotetext{
${ }^{5}$ Apesar de a idéia de linhas de força não ser nova, já que tinha sido repetidamente observada e investigada como uma curiosidade da ciência, foi através das mãos de Faraday que a mesma tornou-se um poderoso instrumento de investigação científica. [5]
} 
missão contínua de força, mesmo que não saibamos como este estado de tensão se produz.

Vemos então que Faraday "percebeu no meio um estado de tensão" (ver Fig. 8). As propriedades físicas desse meio, entretanto precisavam ser esclarecidas. Esta importante questão das características específicas do meio eletromagnético, discutiremos mais adiante. Antes vamos fazer algumas considerações sobre a origem do conceito de campo do ponto de vista matemático.
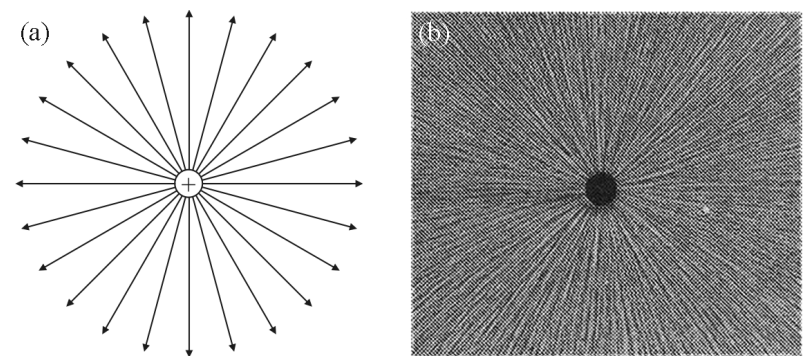

Figura 8 - a) Representação do campo elétrico através de linhas de força, para o caso de uma carga pontual; b) Visualização das linhas de força através de fiapos de tecidos suspensos em óleo (Foto de Harold M. Waage. Princeton University. Adaptada do livro Física, de P.A. Tipler, [10, p. 606]. Esta figura poderia ser obtida também com pequenos pedaços de fibra de sisal, em lugar de fiapos de tecidos. Comparar com a Fig. 2

\section{O campo como uma função matemá- tica: o campo nos meios contínuos}

Nosso propósito neste item é expor como se deu a extensão da noção de campo, como uma função matemática, associada inicialmente apenas aos meios contínuos, para a noção de campo desvinculada desse substrato material. De acordo com Einstein [11]:

[...] o fato do conceito de campo emanciparse da necessidade de um substrato material pertence aos processos psicológicos mais interessantes no desenvolvimento do pensamento físico.

Para entendermos este processo, devemos recordar que o ponto de vista inicialmente adotado pela mecânica newtoniana era o de que a matéria era constituída, em princípio, por pontos materiais. Nos problemas em que a matéria era imaginada como contínua, ou seja, nas situações em que não se estava interessado ou não se podia descrever sua estrutura discreta, as pequenas partes da matéria (elementos de volume) eram tratadas como pontos materiais. Isto é o que foi feito, por exemplo, pelo físico e matemático ítalo-francês Joseph L. Lagrange (1736-1813), no século XVIII, ao descrever o movimento dos fluidos. A cada partícula do fluido (elemento infinitesimal de volume) eram atribuídas as coordenadas $x, y, z$, as quais eram expressas em função do tempo. Esta não era, entretanto, a única maneira de se descrever o movimento de um fluido. Outros cientistas preferiram adotar outro ponto de vista, a exemplo do físico e matemático suíço, Leonardo Euler (1707-1783), que preferiu recorrer ao que chamamos conceito de campo como uma função matemática no interior da matéria ordinária. Nessa descrição do movimento de um fluido, não se procurava especificar o comportamento de cada partícula (elemento de volume), a cada instante; em lugar disto, especificava-se a densidade $\rho(x, y, z, t)$ e a velocidade $\mathbf{v}(x, y, z, t)$ do fluido em cada ponto do espaço, a cada instante. Portanto, concentravam-se as atenções no que ocorria em um ponto particular do espaço em um instante particular e não no que estava acontecendo a uma determinada partícula do fluido. Vemos então que, no quadro da física clássica, o conceito de campo foi criado como uma idéia auxiliar para o estudo dos problemas em que a matéria era tratada como contínua.

Mas não foi só na descrição do movimento dos fluidos que o conceito de campo como uma função matemática se mostrou útil. Ele foi usado também no estudo da transmissão da energia sob a forma de calor em corpos sólidos, realizado pelo físico e matemático francês Jean. B. Fourier (1768-1830), entre 1807 e 1822. Nesse período, Fourier estabeleceu sua famosa equação geral de propagação do calor, a qual pode ser datada de 1807, ano no qual Fourier apresentou sua Memória sobre o Calor, já que entre 1807 e 1822 o que houve foi um aperfeiçoamento das idéias iniciais que culminaram com a publicação da sua Teoria Analítica do Calor, nesta última data.

Para entendermos melhor o que foi dito, consideremos o problema da transmissão de energia na forma de calor em um corpo sólido. Neste caso, o estado do corpo é descrito indicando-se a temperatura, $T$, de cada ponto do corpo, em um determinado instante. Na equação obtida por Fourier, a temperatura, $T$, isto é, o campo de temperatura, aparece como uma função matemática das coordenadas e do tempo, $T=T(x, y, z, t)$, como podemos ver

$$
\frac{\partial T}{\partial t}=-\kappa\left[\frac{\partial^{2} T}{\partial x^{2}}+\frac{\partial^{2} T}{\partial y^{2}}+\ldots\right],
$$

que é a equação do calor, devida a Fourier.

A dedução da equação do calor, conforme feita por Fourier, pode ser vista no Apêndice. A solução desta equação para o caso do problema da condução do calor em apenas uma dimensão, onde $T$ é uma função somente de $x$ e de $t$, entretanto, pode ser facilmente obtida se nos restringirmos ao fluxo de calor estacionário, isto é, independente do tempo. E é isto o que vamos fazer a seguir.

Consideremos então, como exemplo, o caso de uma barra com as extremidades ligadas a duas fontes térmicas, com apenas as laterais cobertas por um isolante térmico ideal (Fig. 9). 


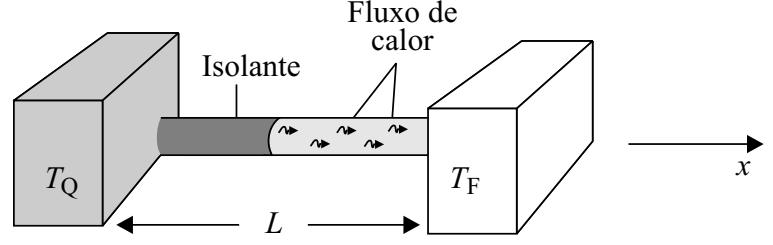

Figura 9 - Barra com extremos ligados a duas fontes térmicas.

Como o fluxo de calor é suposto ser estacionário, então, $\partial T / \partial t=0$ e, consequentemente, $-\kappa\left[\left(\partial^{2} T / \partial x^{2}\right)\right.$ $+\ldots]=-\kappa\left(\partial^{2} T / \partial x^{2}\right)=0$. Como decorrência desse resultado, podemos escrever

$$
\frac{\partial T}{\partial x}=a \text { ou } T(x)=a x+b,
$$

onde $a$ e $b$ são constantes de integração.

Considerando agora que em

$$
x=0, \quad T(0)=b=T_{Q}
$$

e que em

$$
x=L, \quad T(L)=a L+b=a L+T_{Q}=T_{F},
$$

então

$$
T=T(x)=-\left[\frac{\left(T_{Q}-T_{F}\right)}{L}\right] x+T_{Q},
$$

que é o campo de temperatura, procurado.

Vemos então que os campos acima referidos ocorrem apenas no interior da matéria ordinária, onde o calor é transmitido por condução (o que pressupõe ação de partes em contato). Com estes campos, seria possível descrever-se um estado desta matéria. Nos lugares onde não houvesse matéria, não poderia existir campo. Isto se quiséssemos estar de acordo com a gênese do conceito de campo, como uma função matemática.

Entretanto, nas primeiras décadas do século XIX, a física passou por um processo de grandes descobertas e renovação. Isto se deu especialmente com as descobertas de Thomas Young e Augustin Fresnel relacionadas à natureza da luz e com a descoberta fundamental de Oersted, da relação entre a eletricidade e o magnetismo. Uma das consequências dos trabalhos de Young e Fresnel foi a retomada do conflito científico entre os modelos corpuscular ou ondulatório para a luz, conflito este que teve sua origem nos trabalhos de R. Descartes (15951650), C. Huygens (1629-1695), I. Newton e outros cientistas do século XVII.

Ao estudar os fenômenos luminosos, Young, que era médico e se interessava pelos problemas de visão, descobriu, entre os anos 1801 e 1803, o que ele chamou de "lei geral da interferência da luz". Inspirado em efeitos observados em experiências com ondas na água e com ondas sonoras, ele foi capaz de mostrar que os resultados de experiências semelhantes, feitas com luz passando através de duas fendas (ou dois furos, pequenos), poderiam ser explicados de forma simples se a luz fosse considerada como uma onda e não como uma partícula. Logo em seguida, ainda nas duas primeiras décadas do século XIX, Fresnel, num trabalho igualmente extraordinário, consolidou a concepção da luz não só como onda, mas também como uma onda transversal, dando um passo a frente de Huygens que, junto com outros físicos do século XVII, consideravam a onda luminosa semelhante a uma onda sonora, que é longitudinal. Com base no modelo ondulatório, os fenômenos de interferência e de propagação da luz puderam ser explicados com bastante simplicidade, tomando-se a luz como um campo de ondas perfeitamente análogo ao campo das oscilações mecânicas em um sólido elástico. Este campo existiria mesmo na ausência da matéria ordinária, o que, sem dúvida, parecia um paradoxo. A este respeito, Einstein afirma [11]:

[...] Foi necessário introduzir um campo que agora era capaz de existir também no espaço vazio, na ausência da matéria ponderável.

Este estado de coisas criou uma situação paradoxal, porque o conceito de campo, de acordo com a sua origem, parecia restrito a descrever estados no interior de um corpo ponderável.

Vemos então que, até essa época, o campo era pensado como algo capaz de descrever um estado no interior da matéria ordinária. Com a extensão do conceito de campo para o espaço, fora da matéria ponderável, surgiu a necessidade de se retomar a idéia do éter aristotélico-cartesiano que admitia, em toda parte, inclusive no espaço considerado vazio, a existência de um meio ou substância material de propriedades no mínimo curiosas. A origem remota e o desenvolvimento da idéia de éter é o que veremos a seguir.

\section{O éter}

A idéia de um meio (sutil e misterioso) que preencheria o espaço remonta à Grécia antiga. 6

Para Aristóteles (384-322 a.C.), o éter era um fluido puro e transparente que preencheria a chamada esfera celeste. Dentro da sua visão da natureza e de acordo com a dualidade de sua física (terrestre e celeste), Aristóteles aprimorou a idéia dos quatro elementos de Empédocles: terra, fogo, ar e água, e admitiu que tais elementos comporiam apenas as coisas da Terra, de forma que o espaço celeste seria formado por um quinto elemento - o éter. Sendo estranho ao mundo sublunar, o quinto elemento, a que ele chamou de éter, não poderia transformar-se em outras substâncias e seria incorruptível e eterno, como o mundo celeste. O éter seria uma substância que se distinguiria de todas as formas

\footnotetext{
${ }^{6}$ De acordo com alguns estudiosos, o termo aithér deriva do verbo aítho, e o significado desse verbo e de seus derivados como aithér, envolve não só a noção básica de queimar, abrasar, mas também aspectos secundários desse fenômeno como brilho do fogo.
} 
de matéria. Mais tarde, na Idade Média, os aristotélicos a denominaram de "quinta essência".

Por quase 2000 anos, prevaleceram na física as idéias aristotélicas como um todo e, consequentemente, a idéia de éter defendida por Aristóteles. No século XVII, entretanto, a idéia do éter sofreu modificações com os trabalhos de Descartes, Huygens, Newton e outros. Descartes, por exemplo, dentro de sua visão do universo, aceitava a existência de um meio ou substância entre os corpos materiais, e esse meio seria um fluido que ocuparia todo o espaço, inclusive os poros destes corpos. Para ele, "uma matéria muito sutil", o éter (termo que ele não usou talvez para não ser confundido com o éter aristotélico) seria o intermediário das ações dos sistemas físicos, especialmente os ópticos; e a luz, essencialmente, um movimento ou ação que se transmitia através desse meio. Em La Dioptrique (1637), Descartes escreveu [12]:

[...] recorde-se a natureza que atribuí à luz, quando afirmei que esta não é mais do que um certo movimento ou ação, no seio de uma matéria muito sutil que enche os poros de todos os corpos.

É a partir dessas idéias que Huygens concebe seu meio propagador da luz, com características tais que explicassem o fato da luz ter uma grande velocidade, por ele já avaliada, a partir da descoberta de Roemer, em 230.000 km/s. Em 1678, Huygens melhorou e ampliou a hipótese ondulatória da luz, proposta por Robert Hooke (1635-1703) e pelo padre jesuíta Ignácio Pardiès (16361673). O fio condutor do raciocínio de Huygens foi a analogia com o som, que é uma vibração mecânica em meios como o ar, os sólidos e os líquidos. Como o som não se propaga no vácuo, e a luz propaga-se (também) nele, Huygens então precisou conceber a existência de um meio luminoso, que penetrava os poros de todos os corpos e enchia todo o espaço. Este meio seria para ele um fluido, batizado de éter luminífero, apoiado no éter aristotélico-cartesiano.

Em 1817, as discussões em torno desse meio elástico especial, cujas propriedades eram essencialmente diferentes daquelas que têm os meios elásticos comuns, ganham uma nova dimensão, e isto ocorre devido à hipótese da transversalidade da onda luminosa, introduzida por Young, na tentativa de explicar os fenômenos relacionados à dupla refração. Como consequência destas idéias de Young, o físico francês $\mathrm{Au}-$ gustin Fresnel foi levado a introduzir um novo modelo para o éter luminífero. O éter de Fresnel deveria comportar-se como um sólido elástico, e não como um fluido, como queria Huygens e outros. De acordo com este modelo, o éter deveria ser rígido, pois sendo a luz uma onda transversal, não se propagaria (da mesma forma que as ondas mecânicas transversais também não o fazem) através de um meio fluido. Mas, simultaneamente, o éter teria que ser muito tênue para, por exem- plo, não oferecer resistência ao movimento dos planetas. A propósito desse modelo para o éter, Young observou $([2$, p. 25]):

[este modelo] é pelo menos bastante engenhoso e pode dar origem a alguns cálculos satisfatórios; no entanto, dele faz parte uma circunstância que tem consequências desastrosas... a resistência lateral tem sido apenas atribuída a sólidos; de modo que... se pode inferir que o éter luminífero que enche todo o espaço e penetra quase todas as substâncias é não só altamente elástico como também totalmente sólido!!!

Apesar das dificuldades inerentes a tal modelo - devido ao fato dele exigir propriedades contraditórias para o éter - a hipótese da sua existência perdurou por muito tempo, recebendo, inclusive, um reforço significativo na década de 1860, após Maxwell demonstrar que a luz era uma onda eletromagnética.

Com a teoria eletromagnética da luz criada por Maxwell, o éter deixaria de ter natureza necessariamente mecânica, como até então, pois, nessa teoria, as propriedades do meio eletromagnético deveriam ser idênticas às do meio luminífero. No seu livro publicado em 1873, Maxwell escreveu ([13, p. 431]):

Em muitas partes desse tratado tentamos explicar fenômenos eletromagnéticos por meio de ação mecânica transmitida de um corpo a outro através de um meio ocupando o espaço entre eles. A teoria ondulatória da luz também supõe a existência de um meio. Agora mostraremos que as propriedades do meio eletromagnético são idênticas àquelas do meio luminífero.

Apesar de ter sido proposto, inicialmente, como meio propagador da luz, o éter poderia agora ser pensado também como meio propagador das ondas elétricas e magnéticas. Para Maxwell, independentemente das dificuldades que pudéssemos ter para formar uma idéia consistente sobre a constituição do éter, não poderia haver qualquer dúvida de que os espaços interplanetários e interestelares não eram vazios, mas sim ocupados por uma substância material.

Vemos, então, que a idéia do que seria o éter mudou ao longo do tempo. Por volta de 1887, acreditavase que o éter seria um meio sutil, infinitamente mais tênue que os gases mais leves, absolutamente inerte e perfeitamente elástico. Tal substância ou corpo seria uma espécie de quarto estado físico da matéria que preencheria os intervalos ou poros moleculares, penetrando intimamente todos os corpos compostos da matéria ordinária, quer esta estivesse em estado sólido, líquido ou gasoso. Além disso, o éter seria encontrado não só na vizinhança da Terra e serviria de in- 
termediário universal entre todos os constituintes do universo.

A hipótese da existência do éter teve sua primeira grande dificuldade após as famosas experiências realizadas pelo físico alemão, naturalizado norte-americano Albert A. Michelson (1852-1931), algumas das quais realizadas em colaboração com o químico norteamericano, Edward W. Morley (1838-1923), em 1887. Nessas experiências, eles tentaram verificar o efeito da velocidade do referencial do observador (Terra) na medida da velocidade da luz viajando no suposto éter. Como tal efeito não foi detectado, colocou-se em séria dúvida a existência do éter.

Mas os cientistas não estavam dispostos a abandonar a idéia do éter tão facilmente. Os resultados dos experimentos de Micheson-Morley surgiram num contexto em que os físicos estavam buscando a formulação de uma teoria eletromagnética mais ampla do que a de Maxwell para esclarecer vários fenômenos físicos que estavam ficando sem explicaçãd ${ }^{7}$ dentro do quadro das teorias físicas então existentes. O cientista mais bem sucedido neste propósito foi o físico holandês H.A. Lorentz (1853-1928) que, a partir de 1880, apoiado na hipótese do éter, desenvolveu sua teoria eletromagnética (chamada às vezes teoria dos elétrons) apresentando a forma final da mesma em 1904. Neste $^{\text {N }}$ período, Lorentz explicou inclusive os resultados negativos dos experimentos de Michelson-Morley, acrescentado à sua teoria a chamada hipótese da contração (1892).

Baseado em um ponto de vista bastante diferente do de Lorentz, Albert Einstein (1879-1955) entra em cena em 1905 com a teoria da relatividade restrita. Einstein havia tomado conhecimento dos trabalhos de pesquisa de Lorentz já há algum tempo, mas, diferentemente de Lorentz, não considerou a hipótese do éter na formulação da sua teoria, o que, naturalmente, geraria muita polêmica. Em seu artigo de 1905, Einstein escreveu [14]:

A introdução de um "éter luminífero" revelar-se-á supérflua visto que na teoria que vamos desenvolver não necessitaremos de introduzir um "espaço em repouso absoluto".

Apesar de a teoria eletromagnética do éter, de Lorentz, e a teoria da relatividade restrita, de Einstein, serem, do ponto de vista dos resultados experimentais, praticamente equivalentes, em pouco tempo a teoria de Einstein prevaleceu sobre a teoria de Lorentz.

Mas a discussão sobre a hipótese da existência do éter não se encerra com a publicação da teoria da relatividade restrita (nem com a publicação da teoria da relatividade geral, 11 anos depois). Em 1916, Einstein, numa carta a H. Lorentz, escreve [15]:

Eu concordo com você que a teoria da relatividade geral admite uma hipótese do éter assim como a teoria da relatividade especial.

Em maio de 1920, diante da polêmica surgida em torno da idéia do éter (com a publicação da teoria da relatividade restrita e geral), Einstein, a pedido de Paul Ehrenfest e após ter aceitado o convite da Universidade de Leyden para ser professor especial daquela universidade (o que envolvia visitas de algumas semanas por ano), fez uma conferência sobre Ether and the Theory of Relativity, quando, após apresentar uma revisão histórica do conceito de éter, afirmou [15, 16]:

A posição que poderia ser assumida, em seguida, parecia a seguinte: o éter não existe, os campos eletromagnéticos não são estados de um meio e não estão ligados a qualquer transportador mas são realidades independentes que não podem ser reduzidas a nenhuma outra coisa, exatamente como os átomos da matéria.

e mais adiante ele diz:

Uma reflexão mais cuidadosa nos ensina, no entanto, que a teoria especial da relatividade não nos obriga a negar o éter. Podemos assumir a existência do éter; apenas devemos desistir de lhe atribuir um estado definido de movimento.

Negar o éter seria, em última instância, assumir que o espaço vazio não tem nenhuma propriedade física, mas, para Einstein, esta visão não se harmoniza com os fatos fundamentais da mecânica. "Newton poderia ter chamado seu espaço absoluto de 'éter', o essencial é apenas que, além dos objetos observáveis, há outra coisa, não perceptível, que deve ser considerada real, para podermos considerar a aceleração ou a rotação como algo real". No último parágrafo de sua conferência Einstein resume:

Recapitulando, podemos dizer que de acordo com a teoria da relatividade geral, o espaço é dotado de qualidades físicas; neste sentido, portanto, existe um éter. De acordo com a teoria da relatividade geral, espaço sem éter é impensável; pois, em tal espaço, não haveria propagação da luz nem possibilidades de padrões de espaço e tempo (réguas e relógios), nem intervalos de espaço-tempo no sentido físico. Mas este éter não pode ser dotado da qualidade dos

\footnotetext{
${ }^{7}$ Como, por exemplo, a emissão e absorção da radiação térmica, e a dispersão normal e anômala (dependência do índice de refração com a frequência).

${ }^{8}$ Para Lorentz, "O mundo físico consiste de três coisas separadas, três tipos de material fundamental: primeiro a matéria ordinária tangível, segundo os elétrons, terceiro o éter ..."
} 
meios ponderáveis, que consistem em partes que podem ser seguidas ao longo do tempo. A idéia de movimento não pode ser aplicada a ele.

Vemos então que Einstein afirma existir uma diferença entre o éter compatível com a teoria da relatividade e o éter clássico (pré-relativístico). Este novo éter depende, por exemplo, da influência da matéria em pontos próximos, ao passo que o éter clássico, de Lorentz, seria igual em todos os pontos.

Mesmo hoje, a idéia da existência do éter não perdeu seu brilho. Após retornar à física através da relatividade geral de Einstein, a idéia de éter vem sendo também considerada, de outra forma, na teoria quântica. Nesta, a idéia do éter retorna através do conceito de vácuo quântico que, conforme nos lembra R. Martins [15], pode ser tudo, menos vazio.

Muitos cientistas evitam usar o termo éter. Este termo ainda é um tabu. Mas não se pode negar que o desenvolvimento científico exigiu a introdução de novos conceitos semelhantes ao conceito de éter clássico, adotado na segunda metade do século XIX.

\section{O campo eletromagnético: de Fara- day a Maxwell}

Em meados do século XIX, pesquisas muito importantes sobre eletricidade e magnetismo estavam sendo feitas na Alemanha, por físicos e matemáticos alemães e eram baseados na teoria de ação a distância. As idéias que guiaram os trabalhos de A.M. Ampère (17751836), na França, pertenciam também a esta escola. $\mathrm{Na}$ Inglaterra, entretanto, uma visão completamente diferente tinha sido adotada por Faraday: aquela que admitia a presença de um meio entre os corpos, e a ação entre eles se dando através deste meio - de uma porção à porção contígua. É neste estágio crucial para o desenvolvimento do eletromagnetismo que surgem os trabalhos de J.C. Maxwell. (Fig. 10).

Maxwell se beneficiou inteligentemente dos trabalhos desenvolvidos por William Thomson (Lord Kelvin) (1824-1907), um eminente físico, matemático e engenheiro, nascido em Belfast, na Irlanda, de família escocesa que, com 17 anos, influenciado pela obra de Fourier, (conhecia também as obras de Lagrange e Laplace) tinha mostrado que as equações utilizadas na formulação e resolução de problemas de eletrostática podiam ser usadas para resolver problemas de transferência de calor. Num trabalho de 1842, Kelvin compara distribuição de força eletrostática, em uma região contendo condutores eletrizados, com a distribuição de fluxo de calor em um sólido suficientemente grande para que detalhes do seu contorno pudessem ser desprezados (evitando assim complicar o estudo); as superfícies equipotenciais em um caso correspondem às superfícies isotérmicas no outro, e a carga elétrica corresponde a uma fonte de calor. Curiosamente, seus resultados mostraram que as respostas matemáticas ao problema elétrico eram semelhantes as dos problemas de transferência de calor. Tal comparação, tal exercício matemático, era aparentemente (só aparentemente) de pouca valia, pois, nessa época, a eletrostática era tratada de forma simples e eficaz com base na idéia de ação a distância e o mecanismo de transferência de calor, que pressupunha ação de partes em contato, não parecia ter análogo na eletricidade. Maxwell, porém, viu nos trabalhos de Kelvin uma idéia inteiramente nova. Maxwell diria, posteriormente, que o trabalho de Kelvin "introduziu na ciência matemática a idéia de ação elétrica conduzida através de um meio contínuo" [17, p. 241]. Esta era a mesma idéia proposta por Faraday, mas nunca antes trabalhada do ponto de vista matemático. Em 1846, Kelvin desenvolve um pouco mais este assunto e, adotando a idéia de um meio permeando todo o espaço, o éter clássico (Faraday preferia preencher o espaço não com o éter, mas com as linhas de força), compara os efeitos elétricos no éter com as variações encontradas em um corpo sólido submetido a tensões. Era uma idéia que prometia esclarecer como tal éter podia transmitir efeitos de um lugar para outro. Nas mãos de Maxwell, as concepções de Kelvin foram desenvolvidas com admirável imaginação, a partir de 1855 .

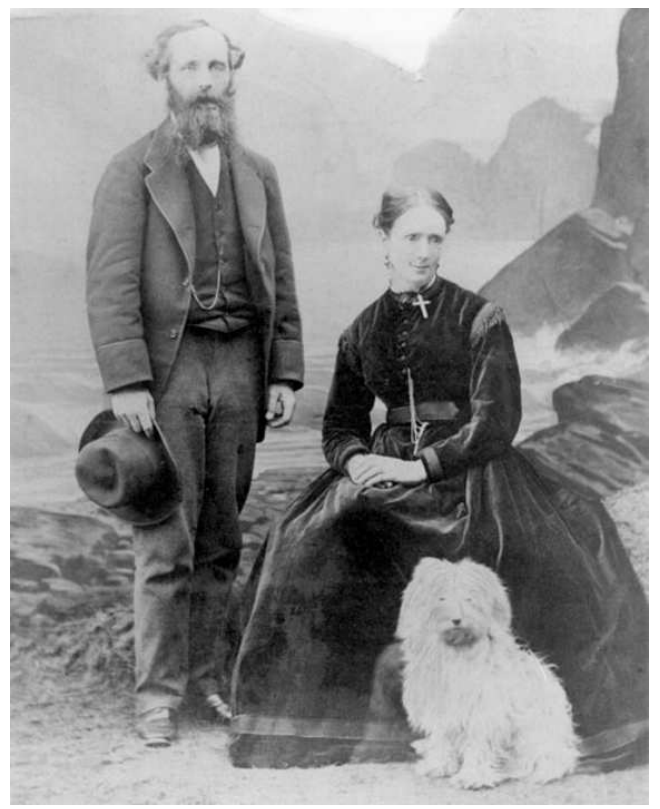

Figura 10 - James C. Maxwell e esposa, em 1869.

Maxwell era um grande matemático e naturalmente sabia que uma mesma equação matemática podia adquirir significados físicos diferentes, dependendo do contexto teórico e do objeto físico a que se referisse. Em 1856, Maxwell assim se refere aos resultados dos trabalhos desenvolvidos por Kelvin [18]:

[... As leis de condução de calor em um 
meio uniforme parecem, à primeira vista, muito diferentes em suas relações físicas quando comparadas com as leis de atração. Nelas as quantidades que entram são a temperatura, o fluxo de calor e a condutividade. A palavra força é estranha a este assunto. No entanto, descobriu-se que as leis matemáticas para o movimento uniforme de calor em meio homogêneo são idênticas às leis de atração, variando com o inverso do quadrado da distância $[\ldots]$

Maxwell, porém, não era só um grande matemático. Ele era também um físico extraordinário e percebeu que o mecanismo físico de transferência de calor por ação de partes em contato (de uma porção à porção contígua) poderia ter seu equivalente no contexto do eletromagnetismo se para isso fossem adotadas as concepções de Faraday, em lugar da idéia de ação a distância, que prevalecia entre os matemáticos, conforme citamos anteriormente. Acreditou então que, assim fazendo, poderia encontrar uma teoria mais consistente fisicamente que aquela formulada pelos matemáticos do continente europeu, baseada na concepção de ação a distância. No seu tratado, publicado em 1873, Maxwell escreveu ([13, p. viii]):

[... antes de iniciar o estudo de eletricidade, eu resolvi não ler a matemática sobre o tema sem primeiro ler as "Pesquisas Experimentais em Eletricidade", de Faraday. Eu estava atento para a suposta existência de uma diferença entre a maneira de Faraday conceber os fenômenos e a maneira dos matemáticos, tal que nem ele e nem eles ficaram satisfeitos com a linguagem um do outro. Eu também tinha a convicção que essa discrepância não tinha origem em nenhum erro. Fui primeiro convencido disso por Sir William Thomson, cuja orientação e assistência, bem como suas publicações, propiciaram o que eu tenho aprendido sobre o assunto.

Quando eu prossegui com o estudo de Faraday, percebi que seu método de conceber os fenômenos foi também matemático, apesar de não exibido na forma convencional de símbolos matemáticos. Eu também achei que seus métodos foram capazes de ser expressos nas formas matemáticas ordinárias, e então comparados com aqueles dos matemáticos. Por exemplo, Faraday visualizava linhas de força atravessando todo o espaço onde os matemáticos viam centros de força atraindo-se a distância. Faraday visualizava um meio onde eles nada viam, somente distância. Faraday procurava a base dos fenômenos em ações que se processavam num meio, eles se satisfaziam ao tê- las achado num poder de ação a distância exercido sobre os fluidos elétricos.

Quando eu traduzi de uma forma matemática o que considerei serem as idéias de Faraday, achei que em geral os resultados dos dois métodos coincidem, tal que os mesmos fenômenos foram explicados, e as mesmas leis de ação deduzidas de ambos os métodos, porém, que os métodos de Faraday assemelhavam-se àqueles nos quais começamos com o todo e chegamos às partes por análise, enquanto os métodos matemáticos ordinários baseavam-se sobre o princípio de iniciar com as partes e construir o todo por síntese.

Para Maxwell, seus trabalhos são uma tradução matemática do que ele considera ser as idéias de Faraday. Porém, em lugar de se concentrar nas linhas de força, como Faraday o fez, Maxwell gradualmente foi deslocando sua atenção para a idéia de uma substância que preencheria todo o espaço e que seria responsável pela transmissão dos efeitos elétricos e magnéticos, tendo incorporado ao seu éter, nesse processo, muitas das idéias que Faraday havia desenvolvido para as linhas de força.

No seu famoso tratado sobre eletricidade e magnetismo, Maxwell apresenta uma formulação matemática unificada das leis de Coulomb, Oersted, Ampère, Biot/Savart, Faraday e Lenz, expressando essas leis na forma de quatro equações, conhecidas, hoje, como equações de Maxwell. Uma consequência importante de sua teoria eletromagnética foi a incorporação da óptica ao eletromagnetismo.

\section{O campo após Maxwell}

Como vimos, as experiências realizadas por A. Michelson e E. Morley, em 1887, colocaram em séria dúvida a presença do éter no Universo e, aos poucos, a esperança de explicar o campo com base em concepções mecânicas para o éter, foi se enfraquecendo (o campo elétrico, por exemplo, era imaginado como sendo uma modificação de um meio elástico, análoga a uma tensão neste meio). Apesar de cientistas importantes, a exemplo de Lorentz, continuarem suas pesquisas com base na hipótese do éter, outros passaram a encarar a luz como uma onda que se auto-sustentava e, paulatinamente, as atenções dos cientistas se deslocaram do conceito de éter para o conceito de campo. Ao que parece, foi Hertz (1887) um dos primeiros a postular a validade das equações de Maxwell, sem a necessidade do meio etéreo no qual as ondas se propagariam, e consta que ele o fez por razões didáticas.

Até aqui não discutimos a relação entre campo e energia. Mas é oportuno salientar que a atribuição de energia ao campo, concebida pela teoria eletromagnética de Maxwell (no artigo A Dynamical The- 
ory of the Electromagnetic Field, de 1864), revelou-se mais um passo importante no desenvolvimento deste conceito. A relação de equivalência entre energia e massa estabelecida pela teoria da relatividade restrita, em 1905, entretanto, introduziu novas questões. Se há uma equivalência entre energia e massa, qual seria a relação entre campo e massa, ou melhor, entre campo e matéria? De outro modo: Podemos pensar em campo e matéria como duas realidades diferentes? Quais são os critérios físicos que distinguem campo e matéria?

Ao apreciar estas questões, devemos notar que, até 1905, não havia dificuldade em se distinguir campo e matéria. Todos concordavam que matéria tinha massa enquanto campo não tinha. Com a teoria da relatividade restrita, entretanto, matéria passou a representar enormes reservatórios de energia (e energia a representar matéria) com o campo representando energia onde a concentração desta era pequena. Sendo assim, não haveria como distinguir entre campo e matéria. Não seria possível imaginar, portanto, uma superfície definida separando distintamente campo e matéria (esta mesma dificuldade surge para a carga e seu campo).

Tendo em conta que as leis de Maxwell e da gravitação não são válidas onde as "fontes" do campo (cargas, massas) estão presentes, Einstein sugere, em seu livro Evolução da Fúsica ([19, p. 198]), que se considerássemos a matéria como sendo as regiões do espaço em que o campo é extremamente forte, talvez fosse possível, com base unicamente no conceito de campo, dar uma explicação de todos os acontecimentos da natureza por leis estruturais válidas em toda parte, inclusive onde as "fontes" de campo estão presentes!

Embora todas as interações (a exemplo da gravitacional, da forte e da eletromagnética, ou como diríamos, a partir de 1968, eletrofraca) possam ser descritas por meios de campos, devemos lembrar que nem todo campo corresponde a uma interação. Os campos de temperatura, pressão, e velocidades, por exemplo, não correspondem a nenhuma interação.

\section{O campo em sala de aula}

Em sala de aula, no contexto do ensino tradicional de eletricidade e magnetismo para alunos do segundo ano universitário, da área de ciências exatas, a minha experiência pessoal era a de apresentar o assunto ou capítulo "campo elétrico" nos marcos de uma abordagem matemático-conceitual, com pouca referência nos aspectos histórico-conceituais, pelo menos na extensão sugerida neste artigo. As razões que nos levavam a este tipo de abordagem geralmente estavam relacionadas com o excesso de tópicos a serem cobertos dentro da carga-horária da disciplina. A isto se somava a necessidade reclamada pelos alunos de se fazer um número razoável de exercícios em sala de aula, envolvendo cálculo diferencial e integral, no que geralmente se gastava muito tempo. Esta maneira de apresentar o assunto poderia até resultar num bom "treinamento" para alunos dos cursos de engenharia, por exemplo, mas certamente não é a melhor maneira de abordar o tema, especialmente no que se refere aos alunos do curso de Licenciatura em Física.

Novas experiências em sala de aula, entretanto, têm confirmado que uma abordagem em que os aspectos histórico-conceituais são acrescidos à abordagem tradicional é muito mais adequada para a boa formação do aluno que a abordagem com ênfase apenas nos aspectos matemático-conceituais. É isto o que tenho verificado ao ministrar a disciplina Física Básica III, destinada a alunos do curso de Licenciatura em Física, noturno, da UFBa, cuja ementa prever explicitamente a inclusão de história da física, juntamente com aspectos fenomenológicos e matemáticos, no ensino da eletricidade e magnetismo. Apesar desta nova abordagem ter sido realizada através desta disciplina, a mesma poderia ter sido também realizada através da disciplina tradicional (Física Geral e Experimental III-E), desde que houvesse tempo para tanto. Física Básica III é, às vezes, considerada complementar à disciplina tradicional destinada aos alunos de Licenciatura em Física, noturno.

As vantagens dessa abordagem diferenciada podem ser vistas não só nos conteúdos dos tópicos apresentados neste artigo, os quais, em sua maioria, são aqueles discutidos com os alunos, mas também pelas questões interessantes que surgem em sala de aula. Tais questões geralmente estão relacionadas diretamente com as interações eletromagnéticas, descritas por campos elétricos e magnéticos. Mas tendo em conta que muito dos seus aspectos podem ser estendidos a outros campos, seria útil apresentá-las aqui. São elas:

O que é mesmo o campo elétrico? A presença de uma carga muda realmente as propriedades do espaço em sua volta? O campo elétrico é algo real, ele existe de fato? Não é apenas um recurso útil para descrever os fenômenos físicos? Podemos falar de interação (repulsão ou atração) entre campos (criados por bobinas ou imãs, por exemplo)? Qual a diferença essencial entre o conceito de campo usado na linguagem cotidiana, a exemplo de campo de influência política, e o conceito científico de campo físico?

Ao comentar estas questões, devemos primeiro dizer que o termo campo e muitas outras palavras usadas em física, tais como, velocidade, aceleração, força, energia, trabalho, etc, são, na realidade, com algumas modificações importantes, palavras usadas na linguagem cotidiana. A palavra campo, por exemplo, pode ser usada no sentido de campo de jogo (campo de futebol), campo de influência política, etc. Nesses dois exemplos, o campo pode ser entendido como uma região de interação. No sentido político, o termo campo refere-se também a uma quantidade de influência que varia de local para local, estando associado ainda a uma "fonte", um país que exerce a influência. Mas estas são idéias de campo da linguagem corrente e não há interesse em descrevê-las através de uma função matemática. No caso de um campo físico, entretanto, há necessidade de 
tornar a idéia de campo precisa e isto só ocorre quando é possível associar um valor numérico à intensidade do campo a cada ponto do espaço, num certo instante de tempo e, eventualmente, associar também uma direção e um sentido. Em outras palavras, a idéia de campo físico exige a definição de uma função matemática capaz de expressar todas as propriedades do campo em cada ponto do espaço, num certo instante de tempo.

Quanto ao problema de poder ou não poder falar de interação entre campos, devemos ressaltar que, pelo menos do ponto de vista conceitual, não se deve falar em repulsão ou atração entre campos. Cargas em movimento (corrente) numa bobina, por exemplo, tem um campo a elas associado e este campo exerce uma força sobre cargas em movimento (corrente) na outra bobina e não sobre o campo da outra bobina.

O problema de o que é mesmo o campo elétrico e o de sua realidade, entretanto, exige mais atenção e é conveniente considerarmos separadamente os casos do campo eletrostático e do campo eletromagnético propriamente dito.

\subsection{Caso do campo eletrostático}

Consideremos, por simplicidade, o campo elétrico devido a uma partícula carregada, em repouso. Para dar resposta ao problema de o que é mesmo o campo elétrico, devemos dizer que, do ponto de vista puramente matemático (do campo como uma função matemática), o campo elétrico é um vetor obtido através da solução das equações de Maxwell! No caso particular da partícula carregada, este campo corresponde ao vetor representado por $\mathbf{E}=k\left(q / r^{3}\right) \mathbf{r}$, cujo módulo é $k\left(q / r^{2}\right)$. Esta resposta tem a vantagem de ser razoavelmente precisa, mas certamente é insuficiente ou incompreensível para aqueles que estão iniciando o estudo da física. Vamos então dar um passo adiante e procurar responder esta questão do ponto de vista agora qualitativo, assim podemos enfatizar questões que vão além das equações matemáticas, passando-se do mundo dos símbolos ao mundo das "coisas", descrito por palavras e imagens. Para isto, suponhamos, inicialmente, o espaço vazio, livre de qualquer influência elétrica. Se transportarmos uma carga elétrica para uma região deste espaço, cada ponto do mesmo adquirirá propriedades que antes não tinha (é como se o espaço deixasse de ser "neutro"). A estas novas propriedades associadas a cada ponto do espaço (à qual podemos associar um valor numérico), a esta "atmosfera elétrica" existente em torno da carga, chamamos campo elétrico (ver parte inicial deste trabalho).

Note que a partícula carregada tem um campo em torno de si, independente de existirem outras cargas por perto que possam "sentir" este campo. Para verificar a ação do campo, precisamos, entretanto, de outra carga. Ao exercer a ação em outra carga, o campo desempenha o papel de transmissor da interação entre elas.

Seria razoável perguntar agora se a presença de uma carga num ponto do espaço realmente muda as pro- priedades do espaço em sua volta, isto é, se o campo elétrico realmente existe. Será que tudo não passaria de uma interpretação forçada? Dito de outro modo: Como devemos conceber um campo de forças? Este deve ser concebido como algo puramente potencial (caso em que a presença de um corpo se limita apenas a descrever a propensão dos corpos de se moverem)? Deve ser entendido em termos de modificações físicas reais de um meio? Bem, se ficássemos restritos ao caso do campo eletrostático, a discussão deste problema não sairia do plano filosófico. Entretanto, se considerarmos o caso do campo eletromagnético propriamente dito, podemos jogar luz sobre este assunto.

\subsection{Caso do campo eletromagnético}

Para dar resposta ao mesmo problema citado anteriormente (de o que é mesmo o campo elétrico), devemos considerar que cargas em movimento produzem o chamado campo eletromagnético (isto é, além do elétrico produzem o campo magnético). A variação do movimento dessa carga perturba o campo eletromagnético e essa perturbação do campo (onda eletromagnética) se propaga no espaço com a velocidade da luz.

Surge então uma questão: A variação do movimento da carga perturba exatamente o que? O campo? O meio? Em 1873, quando ainda se admitia a presença no universo de um éter clássico, Maxwell responderia que a variação do movimento da carga perturba o meio, isto é, diria que o meio recebe os impulsos e os transporta! No artigo Ação a Distância, de 1873, Maxwell escreve $[5]$ :

Ele se estende [referindo-se ao meio eletromagnético] ininterrupto de estrela a estrela e quando uma molécula de hidrogênio vibra em uma estrela da constelação do Cão, o meio recebe os impulsos desta vibração, e depois de transportá-los em seu imenso regaço por três anos, entrega-os no devido tempo, de maneira regular, ao espectroscópio do...

Mas o meio eletromagnético a que Maxwell se refere aqui é o éter clássico e vimos que hoje não devemos falar mais no éter clássico. Ora, se não mais podemos defender o éter clássico, então deveríamos responder que o movimento da carga perturba o campo (e não o meio) e esta perturbação se propaga, afastando-se da carga (onda eletromagnética). Do ponto de vista mecânico, isto é equivalente a dizer que o movimento de um pistão oscilante perturba (ou altera) a densidade do ar numa certa região de um tubo, e esta perturbação (esta alteração) se propaga em forma de onda no tubo. Afirmamos que se propaga em forma de onda porque uma onda aparece quando uma perturbação criada numa região produz, num instante posterior, uma perturbação em regiões adjacentes. 
Voltando ao eletromagnetismo. Se uma carga elétrica é forçada a oscilar, a oscilação da carga produz um campo elétrico em alteração, que se faz acompanhar (em regiões adjacentes) de um campo magnético em alteração, que por sua vez se faz acompanhar de um campo elétrico em alteração, e assim por diante. Mas "que tipo de alteração se está espalhando no campo de uma onda eletromagnética"? "Apenas as alterações de um campo eletromagnético", responde Einstein $([19$, p. 123]).

Surge agora outra questão: E o que transportam estas ondas eletromagnéticas? Elas têm propriedades mecânicas? Isto é, elas transportam energia, momento linear e momento angular? Bem, ao descrevermos o movimento associado a uma onda, devemos distinguir dois aspectos do mesmo: i) o movimento da onda através do meio (através dos campos, no caso eletromagnético); ii) o movimento oscilatório das partículas do meio (oscilações ou alterações dos campos elétrico e magnético, no caso eletromagnético). É no movimento da onda através dos campos que podemos identificar uma das características mais importantes de uma onda eletromagnética, isto é, o poder de transportar energia de um ponto para outro (A energia do Sol para a Terra, por exemplo). Menos conhecido, entretanto, é o fato de que as ondas eletromagnéticas transportam também momento linear e momento angular. Note que é possível exercer-se uma pressão sobre um objeto fazendo-se incidir ondas eletromagnéticas no mesmo. Se admitirmos como válida a lei da conservação do momento (quantidade de movimento), a pressão da radiação deve ser interpretada como uma prova de que a radiação possui uma quantidade de movimento. A pressão da radiação foi medida por Pyotr Lebedev, em 1901, na Rússia, e por Ernest Nichols e Gordon Hull nos Estados Unidos (usando uma balança de torção), cerca de 30 anos após Maxwell ter predito teoricamente sua existência.

Vemos então que, no âmbito da física, na forma como a física modela a natureza, o uso do conceito de campo não é uma questão apenas de conveniência, ele é mesmo necessário. O exemplo a seguir, adaptado do livro Física de P. Tipler [10, p. 752], reforça esta afirmativa.

Considere a força que um elemento de corrente isolado exerce sobre outro, ou, equivalentemente, a força que cargas aceleradas momentaneamente e, em seguida, desaceleradas bruscamente, exercem uma sobre a outra (Fig. 11). Uma análise cuidadosa revela que não há força sobre o elemento 1 , devido ao elemento 2 (o campo magnético devido ao elemento 2 é nulo pois $I d \mathbf{l}_{2} \times \mathbf{r}$ é nulo), mas há força sobre o elemento 2 devido ao elemento 1. Estas forças, portanto, não obedecem à lei da ação e reação de Newton e isto implicaria na não conservação do momento linear (recorde-se que foi a observação experimental da conservação do momento nas colisões que levou Newton originalmente à lei da ação e reação). Pode-se mostrar, entretanto, que existe força (resultante) sobre o circuito 1 devido ao circuito
2, e vice versa, e que estas forças resultantes obedecem à terceira lei de Newton. Se a discussão ficasse restrita a este caso, o problema da violação da terceira lei estaria resolvido. Mas devemos lembrar que é possível conseguir o equivalente a elementos de correntes isolados mediante a aceleração momentânea de cargas seguidas por uma desaceleração brusca e então a questão da não conservação do momento linear para este sistema passa a ser um problema real! Como superar esta dificuldade? A teoria eletromagnética resolve o problema incluindo no sistema das duas cargas, os campos elétricos e magnéticos. Como aceleração de cargas elétricas produz ondas eletromagnéticas e como a onda eletromagnética é portadora de momento, quando se inclui o campo e o respectivo momento neste sistema, o momento total do sistema é novamente conservado! Na física, o uso do conceito de campo não é, portanto, uma questão apenas de conveniência.

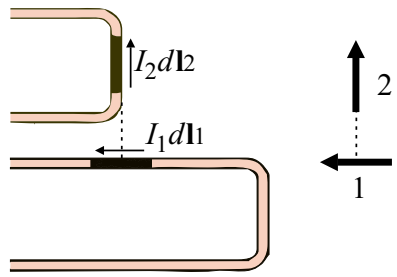

Figura 11 - Elementos de corrente num circuito.

O fato do campo eletromagnético possuir energia indica que, para a física, o campo tem existência tão real quanto as partículas. A criação de pares elétron-pósitron que ocorre durante colisões de raios $\gamma$ ou de partículas carregadas, de energias elevadas, com a matéria (fótons de $300 \mathrm{MeV}$ de energia colidindo com uma chapa de chumbo, por exemplo), aponta nesta direção. Além disso, a teoria eletromagnética (eletrodinâmica clássica) permite mostrar que, pelo menos parcialmente, a massa tem origem eletromagnética [20]. Há também evidências experimentais para a massa eletromagnética, como se pode deduzir da comparação das massas do próton e do nêutron e da comparação das massas dos três tipos de mesons. Os mesons $\pi$ carregados negativamente e positivamente têm uma massa de $139,6 \mathrm{MeV} / c^{2}$, mas a massa do meson $\pi$ neutro $\iota$ de $135 \mathrm{MeV} / c^{2}$ ! Esta diferença de massa tem origem eletromagnética.

Resumindo, podemos dizer que, na sua origem, o conceito de campo parecia apenas um conceito útil. Com o desenvolvimento da física, este conceito foi se tornando cada vez mais real. Para a física moderna o campo eletromagnético e tão real quanto a cadeira que sentamos [19, p. 125].

\section{Comentários finais}

Conforme proposto na Introdução, mostramos que a idéia de campo pode motivar um rico debate sobre a evolução das idéias da física. Para isto apresentamos as primeiras idéias sobre o conceito de campo, 
como diferentes da noção de ação a distância, sem deixar de mostrar que a noção de ação a distância foi usada por renomados cientistas ao longo de muito tempo como uma forma mais simples para se descrever fenômenos eletromagnéticos e mecânicos. Tratamos, em seguida, da noção de campo conforme proposta por Faraday, isto é, como um estado de tensão num meio, expresso por linhas de força, a respeito das quais ele tinha uma concepção física e não uma concepção apenas geométrica (como de fato é admitida atualmente nos livros didáticos). Depois falamos do campo como uma função matemática restrita inicialmente aos meios contínuos e salientamos o interessante processo pelo qual passou o conceito de campo ao emancipar-se do substrato material ao qual o mesmo estava inicialmente vinculado. Mostramos também como a hipótese do éter deu suporte inicialmente à noção do campo fora dos meios materiais (da matéria ordinária) e apresentamos o campo eletromagnético na sua plenitude, conforme proposto por Maxwell. Finalmente, vimos como as atenções dos cientistas foram se deslocando, a partir do final do século XIX, da noção de éter para a noção de campo, sem deixar de salientar que a hipótese do éter não perdeu seu brilho, mesmo nos dias de hoje. Em conclusão, discutimos várias questões interessantes frequentemente presentes durante a exposição deste tema em aulas de eletricidade e magnetismo, destinadas a alunos do segundo ano do curso de Licenciatura em Física, dirigindo nossa atenção especialmente para o problema da realidade do campo eletromagnético. Em razão do exposto, defendemos que, em sala de aula, a proposta de abordagem histórico-conceitual do campo físico, junto com seus aspectos matemáticos, é mais apropriada para uma boa formação do aluno que aquela que enfatiza apenas os aspectos matemáticos deste conceito.

\section{Apêndice: a equação do calor, de Fourier}

Para exemplificar o conceito de campo associado aos meios contínuos, consideremos o caso da transmissão de energia sob a forma de calor em um corpo sólido. $\mathrm{O}$ estudo deste tema feito pelo francês J.B. Fourier (17681830), entre 1807, quando apresentou sua Memória sobre o Calor, e 1822, quando publicou sua Teoria Analítica do Calor. Neste período Fourier estabeleceu sua famosa equação geral de propagação do calor em corpos sólidos.

Para facilitar a exposição, vamos restringir-nos ao caso da condução do calor em uma dimensão, onde $T$ é uma função apenas de $x$ e de $t: T=T(x, t)$. Consideremos então uma barra com as extremidades ligadas a duas fontes e com apenas as laterais cobertas por um isolante ideal (ver figura).

\section{Caso estacionário}

Experimentalmente verifica-se que o calor que flui pela barra, por unidade de tempo, depende da diferença de temperatura, $\left(T_{Q}-T_{F}\right)$; da área, A, da secção da barra; e da distância, $L$, entre as fontes.

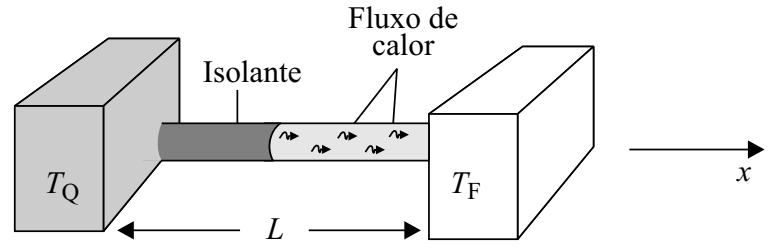

Admitindo que o calor que sai da fonte quente chega à fonte fria (caso estacionário), temos que a quantidade de calor que é transmitida perpendicularmente às faces dos extremos da barra é

$Q_{\text {fluxo de calor, na unidade de tempo }}=\frac{k A\left(T_{Q}-T_{F}\right)}{L}$,

onde $k$, a constante de proporcionalidade, é a condutividade térmica.

\section{Caso não estacionário}

Consideremos agora a situação mais geral do estado não estacionário, onde fluxo de calor, $Q$ (por unidade de tempo), e a temperatura, $T$, são funções da posição e do tempo. Neste caso, podemos admitir como localmente válida a fórmula anterior. Sendo assim

$$
Q \rightarrow Q(x, t) ; \quad T_{Q}-T_{F} \rightarrow-d T ; \quad L \rightarrow d x .
$$

Dessas considerações, podemos reescrever a equação anterior da forma

$$
\begin{gathered}
Q(x, t)=-k A \partial T(x, t) / \partial x . \\
\text { (equação fundamental do calor) }
\end{gathered}
$$

Se agora tomarmos um elemento infinitesimal da barra e aplicarmos a equação anterior para calcular o calor que fica retido por unidade de tempo nesse elemento $d x$ da barra, temos

$$
Q(x, t)-Q(x+d x, t)=\text { diferença de calor }
$$
que entra e sai do elemento $d x$ da barra.

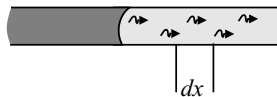

Aplicando a equação anterior, obtém-se então que o calor retido no elemento $d x$, no intervalo de tempo $d t$ é

$$
\begin{gathered}
Q(x, t)-Q(x+d x, t)= \\
-k A \frac{\partial T(x, t)}{\partial x}-(-) k A \frac{\partial T(x+d x, t)}{\partial x} \\
q(x, t)=k A\left[\frac{\partial T(x+d x, t)}{\partial x}-\frac{\partial T(x, t)}{\partial x}\right] d t \\
=k A\left[\frac{\partial^{2} T(x, t)}{\partial x^{2}}\right] d x d t .
\end{gathered}
$$

Este mesmo calor foi gasto para aquecer o elemento da barra, $d x$, durante o tempo $d t$. Se $\rho$ for a massa 
específica, a massa contida em $d x$ é $\rho A d x=m$. Sendo $d T=(\partial T / \partial t) d t$ e $c$ o calor específico, ${ }^{9}$ então

$q(x, t)=c m d T=c \rho A d x\left(\frac{\partial T}{\partial t}\right) d t=k A\left(\frac{\partial^{2} T}{\partial x^{2}}\right) d x d t$,

$\log 0$

$\frac{\partial T}{\partial t}=\left(\frac{k}{c \rho}\right) \frac{\partial^{2} T}{\partial x^{2}}$ (eq. do calor em uma dimensão),

onde o coeficiente $\mathrm{k} / \mathrm{c} \rho=\kappa$ é a difusibilidade térmica.

Esta equação relaciona a variação da temperatura no tempo com a variação de temperatura de um local para outro.

Em três dimensões, $T=T(x, y, z)$, e podemos escrever

$$
\frac{\partial T}{\partial t}=-\kappa\left[\left(\frac{\partial^{2} T}{\partial x^{2}}\right)+\left(\frac{\partial^{2} T}{\partial y^{2}}\right)+\left(\frac{\partial^{2} T}{\partial z^{2}}\right)\right]
$$

que é a equação de propagação do calor, de Fourier.

$\mathrm{Na}$ essência, toda a discussão realizada neste Apêndice foi originalmente desenvolvida por Fourier [21]. De acordo com J. Dias de Deus, Fourier não só obteve esta equação como também a resolveu usando o método das séries de Fourier.

\section{Agradecimentos}

Agradeço aos alunos as discussões realizadas em sala de aula, especialmente a Vinicius Zumaeta Costa pelas suas sugestões.

\section{Referências}

[1] W. Gilbert, De Magnete (Editora Dover, New York, 1991), p. 5 e p. 121. Republicação da tradução de $\mathrm{P}$ Fleury Mottelay, publicada em 1893.

[2] G. Holton, F.J. Rutherford e F.G. Watson, Projecto Física - Luz e Eetromagnetismo. (Fundação Calouste Gulbenkian, Lisboa, 1985), v. 4..

[3] T. Lucrécio Caro, Da Natureza (Editora Globo, Porto Alegre, 1962). p. 199.

[4] M.R. Robilotta, M.J. Bechara e J.L.M. Duarte, $A$ Física e o Eletromagnetismo (Apostila de Física 3, Instituto de Física da USP, 1981), p. 11.
[5] A.C. Tort, A.M. Cunha e A.K.T. Assis, Revista Brasileira de Ensino de Física 26, 273 (2004).

[6] Os Pensadores Pré-Socráticos - Vida e Obra (Editora Nova Cultural Ltda., São Paulo, 1996), p. 41.

[7] I. Newton, The Principia (University of California Press, Berkeley and Los Angeles, 1999), p. 392.

[8] D. Gardelli, Concepções de Interação Física: Subsídios para uma Abordagem Histórica do Assunto no Ensino Médio. Dissertação de Mestrado, Universidade de São Paulo, 2004.

[9] D. Halliday e R. Resnick, Fundamentos de Física, (Livros Técnicos e Científicos Editora S. A., Rio de Janeiro, 1991), v. 3, p. 141,

[10] P.A. Tipler, Física (Editora Guanabara Dois S.A., Rio de Janeiro, 1984), $2^{a}$ ed., v. $2^{a}$..

[11] A. Einstein, A Teoria da Relatividade Especial e Geral (Contraponto, Rio de Janeiro, 1999), p. 120.

[12] E. Hecht, Óptica (Fundação Calouste Gulbenkian, Lisboa, 1991), p. 3.

[13] J.C. Maxwell, A Treatise on Electricity and Magnetism. (Dover Publication, Inc., New York, 1954), v. 2, p. 431 e v. 1, Prefácio à primeira edição, p. viii.

[14] A. Einstein, H.A. Lorentz, H. Weyl and H. Minkowski, The Principle of Relativity (Dover Publications, Inc., New York, 1952 ), p. 38.

[15] R. Martins, Scientific American Brasil - Especial: Erros da Ciência (2006).

[16] A. Einstein, Ether and the Theory of Relativity Conferência apresentada na Universidade de Leyden, em 5 de maio de 1920. Disponível em http://www. tu-harburg.de/rzt/rzt/it/Ether.html Acesso em: $11 / 9 / 2008$.

[17] E. Whittaker, A History of the Theories of Aether and Electricity. (Humanities Press, New York, 1973), p. 241.

[18] F.F. de S. Cruz, Faraday $\&$ Maxwell - Luz sobre os Campos (Odysseus Editora, São Paulo, 2005), p. 185.

[19] A. Einstein e L. Infeld, A Evolução da Física (Editora Guanabara, Rio de Janeiro, 1988), $4^{\mathrm{a}}$ ed.

[20] J. Frenkel, Princípios de Eletrodinâmica Clássica (Edusp, São Paulo, 1996), p. 117.

[21] J.D. de Deus, M. Pimenta, A. Noronha, T. Pena e P. Brogueira, Introdução à Física (McGraw-Hill, Lisboa, 1992), p. 273.

\footnotetext{
${ }^{9} \mathrm{O}$ conceito de calor específico (assim denominado pelo sueco Johan Godolin, em 1784) já tinha sido introduzido na física desde a segunda metade do século XVIII como resultado de trabalhos de vários cientistas, especialmente como resultado das experiências do físico sueco G. W. Richmann, da academia imperial da cidade de São Petersburg, em 1747, e das experiências do físico alemão Johann C. Wilcke, realizadas em 1772 .
} 